\title{
Nutritional Status of Jenukuruba Tribal Children in Mysore District, Karnataka
}

\author{
S.C. Jai Prabhakar and M.R. Gangadhar \\ Department of Anthropology, University of Mysore, Manasagangotri, Mysore 570 006, \\ Karnataka, India \\ E-mail: gangadharmr@yahoo.com
}

KEYWORDS Jenukuruba. Wasting. Stunting. Clinical Observation

\begin{abstract}
A cross-sectional study was undertaken on 135 Jenukuruba tribal children belonging to $6+$ to $10+$ age group through purposive sampling method. Anthropometric measurements and Clinical observation techniques were used to analyse the nutritional status. Assessment of nutritional status using WHO recommended anthropometric indicator and Z-score interpretation revealed, high prevalence of mild $(41.5 \%)$ and severe $(6.7 \%)$ stunting, more prevalence of mild $(40 \%)$ and severe $(3.7 \%)$ in wasting, and underweight was $45.2 \%$ moderate and $14.8 \%$ severity. The BMI value shows $69.6 \%$ were CED-III and only $2.2 \%$ were CED-I. Clinical assessment (using clinical sign of a disease) shows high prevalence of lack of luster and sparseness in hair, conjunctiva xerosis in eyes, angular stomatities in lips, scarlet and raw tongue, dental flurosis in teeth and scabies in skin. Most of the children are mesomorphic in physical appearance.
\end{abstract}

\section{INTRODUCTION}

The physical well being and maintenance of normal health of an individual is closely related to his status of nutrition. Proper nutrition keeps man healthy and fit where as inadequate or improper nutrition reduces fitness and causes susceptibility to disease.

Nutrition plays a vital role, as inadequate nutrition during childhood may lead to malnutrition, growth retardation, reduced work capacity and poor mental and social development (Awasthi and Kumar 1999). Most of the research work that has been conducted on nutritional status of children is limited to infants and preschool children only. There is dearth information on nutritional status of school going children particularly from rural and tribal areas. Keeping this in view, the objective of present study was to access the nutritional status of Jenukuruba tribal children of Mysore district, Karnataka state.

\section{MATERIALS AND METHODS}

The cross-sectional investigation was carried out on 135 Jenukuruba tribal children (58 males and 77 females) belonging to the age group of $6+$ to $10+$ years during the month of June to August, 2007. The samples were collected from different tribal settlements of Hunsur and H.D. Kote taluks of Mysore district, Karnataka state, following purposive sampling technique.
Jenukuruba tribe is principally found in southern parts of India. In Karnataka mainly inhabited in Mysore and Coorg Districts. This tribal population spread over four taluks of Mysore districts and settled in 19 colonies. They are settled in a rehabilitated colony surrounded by forest area. Even though their traditional occupation is honey collection, majority of Jenukurubas are working as a day labourers. Only few of them are cultivating the land. The prefix 'jenu' means honey and kuruba indicates their caste name. Honey collection and agricultural labour are their sources of income. They have their own dialect known as 'Jenu Nudi' and follow the Kannada script. Monogamy is the norm. Cross-cousin marriages are common. In Jenukurubas family is generally nuclear, patriarchal, patrilineal and patrilocal type. They observe defilement both at birth and death. Bore well is the main source of water. Tiled roof houses, agricultural land and equipments were provided by the state Government. No lavatory facility at all. The children use open spaces near by their houses for defecation.

Jenukurubas are mostly non-vegetarian. They ate the flesh of animals they hunted. They relish the flesh of goat, pig, deer, rabbit, hen and other birds etc. and even flesh of dead animals found in the forest. The flesh of the rat is a delicacy, but they avoid beef. They catch fish from the streams. They consume the seasonably available vegetables. They prepare 'sambar' and 
'palye' with vegetables, vegetable leaves and pulses. Tur dal is the main pulses and Ragi is their staple food. On festivals, they prepare sweet i.e. 'payasa'. They consume coffee, tea, milk and milk products. They eat fruits and nuts, which get from the surrounding forest or afford to buy from nearby market. Jenukurubas smoke bidis and chew betel leaves, areca nuts and tobacco. Both men and women consume alcohol.

The anthropometric measurements (Height, Weight, Mid upper arm circumference and triceps skin fold thickness) and Clinical observations of Jenukuruba children were recorded using techniques given by Jelliffe (1966). Height was measured with the help of anthropometric rod and weight by personal weighing balance with minimum clothing. The scale was calibrated against known weights regularly. Mid-upper arm circumference (MUAC) was recorded with the help of flexible measuring steel tape to the nearest $0.1 \mathrm{~cm}$. The thickness of skin fold at triceps was measured using Holtain's skin fold caliper. Height and weight measurements of the children, taking age and sex in to consideration were expressed in terms of Z-score relative to National Center for Health Statistics (NCHS 1983) reference data recommended by World Health Organization (WHO 1983). Thus, those below -2SD of NCHS median reference for height-for-age, weight-forheight, weight-for-age and are defined stunted, wasted and under nutrition respectively. All the individuals were examined clinically for the presence of signs of nutritional deficiency. Statistical analysis was done using SPSS 10.0 software.

\section{RESULTS AND DISCUSSION}

The Mean and Standard Deviation values of anthropometric measurements among Jenukuruba tribal children were presented in table 1 according to the age and sex. In both the sexes mean height, weight and weight for height were increased consistently with the increase in age. The maximum mean incremental difference in height in boys was $+6.86 \mathrm{~cm}$ between $7+$ and $8+$ years and $6.08 \mathrm{~cm}$ per year in girls. Mean BMI value decreased in 7+ years and increase with the remaining age.

The mean mid-upper arm circumference (MUAC) of 6+ year's age group children was $14.92 \mathrm{~cm}$ in boys and $14.28 \mathrm{~cm}$ in girls. The maximum and minimum mean annual incremental difference of mid-upper arm circumference of girls is higher than boys. The maximum mean annual increase of mid-upper arm $(+1.32 \mathrm{~cm}$ per year) has occurred between $9+$ and $10+$ years in girls and boys ( $+1.14 \mathrm{~cm}$ per year). Further it is found that in boys the mid-upper arm muscle circumference (MUAMC) is attained between $8+$ years and $9+$ years $(+1.16 \mathrm{~cm}$ per year) and in girls $(+1.06 \mathrm{~cm}$ per year $)$.

Table 1: Mean and Standard deviation of anthropometric measurements among Jenukuruba children

\begin{tabular}{lllrrrrrr}
\hline Age & Gender & & Height & Weight & Weight for height & BMI & MUAC & MUAMC \\
\hline $6+$ & M 15 & Mean & 108.33 & 15.32 & 18.15 & 13.08 & 14.92 & 13.43 \\
& & SD & 2.47 & 1.14 & 0.75 & 1.23 & 1.05 & 1.02 \\
& F 13 & Mean & 103.80 & 14.12 & 16.40 & 13.10 & 14.28 & 13.01 \\
& & SD & 2.44 & 1.33 & 0.68 & 1.06 & 1.39 & 1.47 \\
$7+$ & M 14 & Mean & 110.18 & 15.64 & 18.73 & 12.86 & 15.21 & 13.99 \\
& & S.D. & 2.82 & 1.74 & 0.88 & 1.11 & 1.50 & 1.55 \\
& F 22 & Mean & 11.27 & 15.93 & 18.70 & 12.84 & 15.53 & 14.07 \\
& & S.D. & 5.31 & 1.90 & 1.84 & 1.00 & 1.18 & 1.18 \\
$8+$ & M 13 & Mean & 117.04 & 18.53 & 21.21 & 13.53 & 14.29 & 12.52 \\
& & S.D. & 2.44 & 1.28 & 0.83 & 0.90 & 0.98 & 0.93 \\
& F 14 & Mean & 117.70 & 17.64 & 20.91 & 12.71 & 15.11 & 13.73 \\
& & S.D. & 1.57 & 1.99 & 0.60 & 1.21 & 0.93 & 1.16 \\
$9+$ & M 11 & Mean & 121.10 & 22.00 & 22.64 & 15.02 & 15.04 & 13.68 \\
& & S.D. & 2.78 & 1.55 & 1.18 & 1.30 & 1.03 & 0.83 \\
& F 25 & Mean & 123.78 & 21.44 & 23.60 & 13.96 & 15.98 & 14.50 \\
& & S.D. & 2.77 & 2.76 & 1.37 & 1.40 & 1.25 & 1.27 \\
$10+$ & M 5 & Mean & 125.32 & 22.60 & 24.50 & 14.37 & 16.18 & 14.58 \\
& & S.D. & 2.20 & 2.07 & 1.06 & 0.89 & 0.77 & 1.07 \\
& F 3 & Mean & 124.77 & 22.00 & 24.03 & 14.13 & 17.30 & 15.15 \\
& & S.D. & 1.66 & 1.32 & 0.90 & 0.81 & 1.57 & 1.43 \\
\hline
\end{tabular}


Table 2 shows the prevalence of stunting. About $41.5 \%$ of mild (-2 SD to $-1 \mathrm{SD}$ ) stunting was recorded in all the age groups and gender, followed by moderate $(39.3 \%)$ and severe (<median $-3 \mathrm{SD}$ ) was $6.7 \%$. Only $10.4 \%$ children were normal in their height for age. The Contingency Coefficient (c.c.) and significance value reveals that, significant association was found among $7+$ and 9+ aged children in the prevalence of mild and moderate stunting. But no significant differences $(\mathrm{p}>0.05)$ in the age of $6+, 7+$ and $10+$ between the gender. The Khaire Kunbi children of Maharashtra (Urade et al. 2004) found $44.12 \%$ (25.17\% of Male and $18.95 \%$ of Females) were mildly retarded in their height for age. Shakya et al. (2004) reported that $21.5 \%$ of East Nepal Primary School children were more stunted than wasted (10.4\%).

Wasting (Weight-for-height) indicates the past and long term under nutrition. The table 3 indicates that, there was no significant asso- ciation in the prevalence of wasting between male and female children. At the age of 9+ years significant (0.043) association was found in mild and moderate level of wasting between both sexes. Combining all the gender and age group, $28.9 \%$ of children were normal. A quite low frequency of overweight $(0.7 \%)$ in $9+$ years male was recorded. The results are in coherence to the findings an earlier study conducted by Sankhala et al. (2004) revealed less than $80 \%$ depicting mild and moderate form of malnutrition and Raheela et al. (2002) studied 13\% children were under nourished in Islamabad, Pakistan.

Weight-for-age indicates the under weight of the child (Table 4). $45.2 \%$ of children were moderately malnourished, whereas $4.4 \%$ were normal. Remaining children had mild and severe form of malnutrition. Significant association was found between both the male and female children in the age group of $6+$ with mild, moderate and

Table 2: Age and gender wise height deficit classification (Stunting)

\begin{tabular}{llrrrrrrr}
\hline Age & Total & $<-3 S D$ & $-3 S D$ to- $2 S D$ & $-2 S D$ to- $1 S D$ & -1 SD to Median & $>=$ Median & c.c. & Sig. \\
\hline $6+$ & M 15 & - & $7(46.7)$ & $6(40.0)$ & $2(13.3)$ & - & 0.456 & 0.061 \\
& F 13 & $1(7.7)$ & $11(84.6)$ & $1(7.7)$ & - & - & & \\
$7+$ & M 14 & $6(42.9)$ & $7(50.0)$ & $1(7.1)$ & - & - & 0.579 & 0.001 \\
& F 22 & $1(4.5)$ & $4(18.2)$ & $5(22.7)$ & $9(40.9)$ & $3(13.6)$ & & \\
$8+$ & M 13 & - & $6(46.2)$ & $7(53.80$ & - & - & 0.291 & 0.287 \\
& F 14 & $1(7.1)$ & $3(21.4)$ & $10(71.4)$ & - & - & & \\
$9+$ & M 11 & - & $7(63.6)$ & $4(36.4)$ & - & - & 0.555 & 0.000 \\
& F 25 & - & $1(4.0)$ & $21(84.0)$ & $3(12.0)$ & - & & \\
$10+$ & M 5 & - & $4(80.0)$ & $1(20.0)$ & - & - & 0.281 & 0.408 \\
& F 3 & - & $3(100.0)$ & - & - & - & & \\
\hline Total & 135 & $9(6.7)$ & $53(39.3)$ & $56(41.5)$ & $14(10.4)$ & $3(2.2)$ & &
\end{tabular}

*Figures in parentheses shown in percentage

c.c. $=$ Contingency Coefficient

Table 3: Age and gender wise weight for height classification (Wasting)

\begin{tabular}{llrrrrrrr}
\hline Age & Total & $<-3 S D$ & $-3 S D$ to- $2 S D$ & $-2 S D$ to- $1 S D$ & -1 SD to Median & $>=$ Median & c.c. & Sig. \\
\hline $6+$ & M 15 & $2(13.3)$ & $4(26.7)$ & $7(46.7)$ & $2(13.3)$ & - & 0.287 & 0.473 \\
& F 13 & - & $5(38.5)$ & $5(38.5)$ & $3(23.1)$ & - & & \\
$7+$ & M 14 & $1(7.1)$ & $8(57.1)$ & $2(14.3)$ & $3(21.4)$ & - & 0.315 & 0.266 \\
& F 22 & $1(4.5)$ & $7(31.8)$ & $10(45.5)$ & $4(18.2)$ & - & & \\
$8+$ & M 13 & - & $3(23.1)$ & $6(46.2)$ & $4(30.8)$ & - & 0.271 & 0.545 \\
& F 14 & $1(7.1)$ & $5(35.7)$ & $6(42.9)$ & $2(14.3)$ & - & & \\
$9+$ & M 11 & - & $1(9.1)$ & $1(9.1)$ & $8(72.7)$ & $1(9.1)$ & 0.429 & 0.043 \\
& F 25 & - & $3(12.0)$ & $13(52.0)$ & $9(36.0)$ & - & & \\
$10+$ & M 5 & - & - & $2(40.0)$ & $3(60.0)$ & - & 0.250 & 0.465 \\
& F 3 & - & - & $2(66.7)$ & $1(33.3)$ & - & & \\
\hline
\end{tabular}

*Figures in parentheses shown in percentage

c.c. $=$ Contingency Coefficient 
Table 4: Age and gender-wise weight deficit classification (Underweight)

\begin{tabular}{|c|c|c|c|c|c|c|c|}
\hline Age & Total & $<-3 S D$ & $-3 S D$ to $-2 S D$ & $-2 S D$ to $-1 S D$ & $-1 S D$ to Median & c.c. & Sig. \\
\hline $6+$ & $\begin{array}{l}\text { M } 15 \\
\text { F } 13\end{array}$ & $\begin{array}{r}10(66.7) \\
-\end{array}$ & $\begin{array}{ll}4 & (26.7) \\
8 & (61.5)\end{array}$ & $\begin{array}{r}1(6.7) \\
5(38.5)\end{array}$ & - & 0.576 & 0.001 \\
\hline $7+$ & $\begin{array}{lc}\text { M } & 14 \\
\text { F } & 22\end{array}$ & $\begin{array}{l}6(42.9) \\
4(18.2)\end{array}$ & $\begin{array}{ll}6 & (42.9) \\
8 & (36.4)\end{array}$ & $\begin{array}{r}2(14.3) \\
10(45.5)\end{array}$ & - & 0.332 & 0.107 \\
\hline $8+$ & $\begin{array}{l}\text { M } 13 \\
\text { F } 14\end{array}$ & (10.2) & $\begin{array}{l}9(69.2) \\
9(64.3)\end{array}$ & $\begin{array}{l}4(30.8) \\
4(28.6)\end{array}$ & $1(7.1)^{-}$ & 0.186 & 0.617 \\
\hline $9+$ & $\begin{array}{lc}\text { M } & 11 \\
\text { F } & 25\end{array}$ & - & $\begin{array}{r}3(27.3) \\
10(40.0)\end{array}$ & $\begin{array}{r}7(63.6) \\
11(44.0)\end{array}$ & $\begin{array}{r}1(9.1) \\
4(16.0)\end{array}$ & 0.179 & 0.550 \\
\hline $10+$ & $\begin{array}{ll}M & 5 \\
\text { F } 3\end{array}$ & $\begin{array}{l}- \\
-\end{array}$ & $\begin{array}{l}2(40.0) \\
2(66.7)\end{array}$ & $\begin{array}{l}3(60.0) \\
1(33.3)\end{array}$ & - & 0.250 & 0.465 \\
\hline Total & 135 & $20(14.8)$ & $61(45.2)$ & 48 (35.6) & $6(4.4)$ & & \\
\hline
\end{tabular}

*Figures in parentheses shown in percentage

c.c. $=$ Contingency Coefficient

Table 5: Age and gender wise distribution of mean BMI

\begin{tabular}{|c|c|c|c|c|c|c|c|}
\hline \multirow[t]{2}{*}{ Age } & \multirow[t]{2}{*}{ Total } & \multicolumn{4}{|c|}{ Category/Grade } & \multirow[t]{2}{*}{ c.c. } & \multirow[t]{2}{*}{ Sig. } \\
\hline & & $<14 C E D-I I I$ & 14-15.49CED-II & $15.5-16.49 C E D-I$ & 16.5-22.49 Normal & & \\
\hline \multirow[t]{2}{*}{$6+$} & M 15 & $12(80.0)$ & $3(20.0)$ & - & - & 0.060 & 0.750 \\
\hline & F 13 & $11(84.6)$ & $2(15.4)$ & - & - & & \\
\hline \multirow[t]{2}{*}{$7+$} & M 14 & $10(71.4)$ & $4(28.6)$ & - & - & 0.181 & 0.270 \\
\hline & $\mathrm{F} \quad 22$ & $19(86.4)$ & $3(13.6)$ & - & - & & \\
\hline \multirow[t]{2}{*}{$8+$} & M 13 & $8(61.5)$ & $5(38.5)$ & - & - & 0.266 & 0.152 \\
\hline & F 14 & $12(85.7)$ & $2(14.3)$ & - & - & & \\
\hline \multirow[t]{2}{*}{$9+$} & M 11 & $2(18.2)$ & $6(54.5)$ & $2(18.2)$ & $1(9.1)$ & 0.408 & 0.066 \\
\hline & F 25 & $16(64.0)$ & $6(24.0)$ & $1(4.0)$ & $2(8.0)$ & & \\
\hline \multirow[t]{2}{*}{$10+$} & M 5 & $2(40.0)$ & $3(60.0)$ & - & - & 0.250 & 0.465 \\
\hline & F 3 & $2(66.7)$ & $1(33.3)$ & - & - & & \\
\hline Total & 135 & $94(69.6)$ & $35(25.9)$ & $3(2.2)$ & $3(2.2)$ & & \\
\hline
\end{tabular}

* Figures in parentheses shown in percentage c.c. =Contingency Coefficient

$\mathrm{CED}=$ Chronic Energy Deficiency

severe level of under weight. Remaining children shows no significant association with their gender. Normal weight-for-age children were found to be negligible in both the sexes. From the earlier studies, it was found that $61 \%$ were under nutrition in different grades and only $39 \%$ were normal in eastern Nepal (Shakya et al. 2004) but only $30 \%$ were under nourished among the children of Islamabad, Pakistan by Raheela et al. (2002). Comparing with the present findings Nepal and Pakistan children suffered more from different forms of malnutrition.

The Body Mass Index classification (Urade et al. 2004) is represented in table 5. About $69.6 \%$ of children were suffering from Grade-III type of malnutrition, followed by Grade-II (25.9\%). Both Chronic energy deficiency-I and normal BMI were recorded $(2.2 \%)$ equally. The Contingency Coefficient (c.c.) value and significance value reveals that, no significant association with gender and different grades of Chronic Energy Deficiency in all the age groups. This shows the magnitude and severity of CED a problem. In tribal areas, the chronic energy deficiency is a primary significance rather than overweight. In accordance to present findings, A very high frequency of CED-III (56.87\% among Males and $49.80 \%$ of Females) followed by CED-II was recorded among Khaire Kunbi children of Maharashtra. (Urade et al. 2004)

The study of clinical observation (Table 6) reveals that majority of the children had lack of luster $(94.1 \%)$, sparseness $(94.1 \%)$ and straightness $(83 \%)$ in hair. The skin diseases like scabies $(69.6 \%)$ and xerosis $(65.9 \%)$ were very common in both the sexes, followed by dental flurosis (46.7\%), scarlet and raw tongue, angular stomatities in lips, conjuctiva xerosis in eyes $(34.8 \%)$ and dental caries $(30.4 \%)$. Uppal et al. (2005) found $10.3 \%$ of Scheduled caste children 
Table 6: Distribution of Clinical Status among the Jenukuruba Children

\begin{tabular}{|c|c|c|c|c|c|c|}
\hline \multirow[t]{2}{*}{ Clinical observation } & \multicolumn{2}{|c|}{ Male $(N=58)$} & \multicolumn{2}{|c|}{ Female $(N=77)$} & \multicolumn{2}{|c|}{ Total $(N=135)$} \\
\hline & No. & $\%$ & No. & $\%$ & No. & $\%$ \\
\hline \multicolumn{7}{|l|}{ Hair } \\
\hline Lack of Luster & 52 & 89.7 & 75 & 97.4 & 127 & 94.1 \\
\hline Sparseness & 54 & 93.1 & 73 & 94.8 & 127 & 94.1 \\
\hline Straightness & 46 & 79.3 & 66 & 85.7 & 112 & 83.0 \\
\hline Discoloured & 25 & 43.1 & 32 & 41.6 & 57 & 42.2 \\
\hline Easily Pluck able & 2 & 3.4 & 7 & 9.1 & 9 & 6.7 \\
\hline \multicolumn{7}{|l|}{ Face } \\
\hline Diffuse Pigmentation & 6 & 10.3 & 8 & 10.4 & 14 & 10.4 \\
\hline Moon face & 12 & 20.7 & 6 & 7.8 & 18 & 13.3 \\
\hline \multicolumn{7}{|l|}{ Eye } \\
\hline Pale conjunctiva & 16 & 27.6 & 22 & 28.6 & 38 & 28.1 \\
\hline Bitot spot & 3 & 5.2 & 4 & 5.2 & 7 & 5.2 \\
\hline Conjunctiva xerosis & 20 & 34.5 & 27 & 35.1 & 47 & 34.8 \\
\hline Corneal Xerosis & 19 & 32.8 & 25 & 32.5 & 44 & 32.6 \\
\hline Keratomalscia & 1 & 1.7 & 1 & 1.3 & 2 & 1.5 \\
\hline Photophobia & 0 & 0.0 & 0 & 0.0 & 0 & 0.0 \\
\hline Night blindness & 1 & 1.7 & 1 & 1.3 & 2 & 1.5 \\
\hline \multicolumn{7}{|l|}{ Lips } \\
\hline Angular Stomatities & 14 & 24.1 & 36 & 46.8 & 50 & 37.0 \\
\hline Angular Scars & 23 & 39.7 & 24 & 31.2 & 47 & 34.8 \\
\hline Cheilosis & 8 & 13.8 & 9 & 11.7 & 17 & 12.6 \\
\hline \multicolumn{7}{|l|}{ Tongue } \\
\hline Oedema & 8 & 13.8 & 10 & 13.0 & 18 & 13.3 \\
\hline Scarlet and raw tongue & 28 & 48.3 & 37 & 48.1 & 65 & 48.1 \\
\hline Majenta tongue & 9 & 15.5 & 21 & 27.3 & 30 & 22.2 \\
\hline \multicolumn{7}{|l|}{ Teeth } \\
\hline Mottled enamel & 5 & 8.6 & 8 & 10.4 & 13 & 9.6 \\
\hline Dental caries & 12 & 20.7 & 29 & 37.7 & 41 & 30.4 \\
\hline Dental flurosis & 24 & 41.4 & 39 & 50.6 & 63 & 46.7 \\
\hline \multicolumn{7}{|l|}{ Gum } \\
\hline Spongy bleeding gum & 7 & 12.1 & 7 & 9.1 & 14 & 10.4 \\
\hline \multicolumn{7}{|l|}{ Glands } \\
\hline Thyroid enlargement (visible) & 5 & 8.6 & 8 & 10.4 & 13 & 9.6 \\
\hline Thyroid enlargement (Palpable) & 1 & 1.7 & 10 & 13.0 & 11 & 8.1 \\
\hline \multicolumn{7}{|l|}{ Skin } \\
\hline Xerosis & 37 & 63.8 & 52 & 67.5 & 89 & 65.9 \\
\hline Scabies & 38 & 65.5 & 56 & 72.7 & 94 & 69.6 \\
\hline \multicolumn{7}{|l|}{ Nails } \\
\hline Koilonychia & 13 & 22.4 & 19 & 24.7 & 32 & 23.7 \\
\hline \multicolumn{7}{|l|}{ Leg } \\
\hline Knock Knee & 4 & 6.9 & 3 & 3.9 & 7 & 5.2 \\
\hline \multicolumn{7}{|l|}{ Physical Appearance } \\
\hline Ectomorphs & 21 & 36.2 & 20 & 26.0 & 41 & 30.4 \\
\hline Mesomorphs & 36 & 62.1 & 57 & 74.0 & 93 & 68.9 \\
\hline Endomorphs & 1 & 1.7 & 0 & 0.0 & 1 & 0.7 \\
\hline \multicolumn{7}{|l|}{ Physical Deformities } \\
\hline Straight & 53 & 91.4 & 73 & 94.8 & 126 & 93.3 \\
\hline Stoopy & 5 & 8.6 & 4 & 5.2 & 9 & 6.7 \\
\hline
\end{tabular}

\# Multiple responses

of Amritsar suffered dental caries, among them boys were more than girls. Majority of the children were mesomorphic $(68.9 \%)$ in physical appearance and only $6.7 \%$ were stoopy in physical deformities. A total of $50(37 \%)$ children exhibited signs of vitamin B-complex deficiency, predominantly angular stomatities. This may be due to cereal based diet and leafy vegetables. Scabies was more common among girls (72.7\%) than boys (65.5\%). Shankhala et al. (2004) recorded $40 \%$ of dry and rough skin (40\%) among 6-10 years of children in Udaipur district. In Rajastan $44 \%$ children had one or more ailment (Tewari et al. 2005) 


\section{CONCLUSION}

The present study reveals that, the Jenukuruba tribal children of Mysore district are suffering from different grades of malnutrition. The widespread prevalence of malnutrition in the form of wasting, stunting and under weight. Clinical observation results reveals preventive measures are needed to improve the health and nutrition condition of the Jenukuruba tribal children.

\section{REFERENCES}

Awasthi N, Kumar AP 1999. Nutritional status of hill primary school children. Ind J Nutr Dietet, 36: 45359.

Jelliff DB 1966. The Assessment of the Nutritional Status of the Community. WHO Mongr Sec No53, Geneva: World Health Organization.

NCHS Standards 1983. Nutrition Monitoring and Assessment. In: T Gopaldas, S Seshadari. Measuring Changes in Nutritional Status. Geneva: World Health Organization.

Tewari Pratiba, Shekhawat Nidhi, Choudhary Sanju 2005. Use of Nutritional Anthropometry and Clinical
Examination in the assessment of Nutritional status of children. Man in India, 85(1 \& 2): 49-60.

Raheela MA, Mian, Mohammed Ali, Paola A, Ferroni, Peter Underwood 2002. The Nutritional status of school aged children in an urban squatter settlement in Pakistan. Pakistan Journal of Nutrition, 1(3): $121-123$.

Shankhala Aarti, Sankhala AK, Bhatnagar Bhavna, Singh Alpana 2004. Impact of Intervention Feeding Trial on Nutritional status of 6-10 years old malnourished children. Anthropologist, 6(3): 185-189.

Shakya SR, Bhandary S, Pokharel PK 2004. Nutritional Status and Morbidity pattern among governmental primary school children in the East Nepal. Kathmandu University Medical Journal, II, 2(4): 307-314.

Uppal M, Kumari K, Sidhu S 2005. Clinical Assessment of Health and Nutritional Status of Scheduled Caste Preschool Children of Amritsar. Anthropologist, 7(3): 169-171.

Urade BP, Moyna Chakravarty, Mallick SK 2004. Assessment of Nutritional Status among the Khaire Kunbi children of Maharashtra. J Hum Ecol, 15(2): 135-142.

WHO 1983. Measuring Change in Nutritional Status. Guidelines for Assessing the Nutritional Impact of Supplementary Feeding Programmes for Vulnerable Groups. Geneva: World Health Organization. 